\title{
ESPAÇOS PÚBLICOS E AMBIÊNCIAS URBANAS: UM DIÁLOGO INTERDISCIPLINAR SOB A PERSPECTIVA DO DESIGN SOCIAL E DA PSICOLOGIA AMBIENTAL
}

\author{
PUBLIC SPACES AND URBAN ENVIRONMENTS: AN \\ INTERDISCIPLINARY DIALOGUE FROM THE PERSPECTIVE \\ OF SOCIAL DESIGN AND ENVIRONMENTAL PSYCHOLOGY
}

\section{Santiago Alarcón Acosta \\ Design Industrial pela Pontificia Universidad Javeriana da Colômbia. E-mail: dogor870907@hotmail.com}

Juliano Bitencourt Campos Professor do Programa de PósGraduação em Ciências Ambientais (PPGCA) Coord. do Laboratório de Arqueologia Pedro Ignácio Schmitz (LAPIS) Universidade do Extremo Sul Catarinense (UNESC). Criciúma, SC, Brasil. E-mail: jbi@unesc.net

\section{Teresinha Maria Gonçalves} Professora do Programa de PósGraduação em Ciências Ambientais (PPGCA) Coord. do Laboratório de Meio Ambiente e Desenvolvimento Urbano e Psicologia Ambiental (LADUPA) Grupo Interdisciplinar e Interinstitucional de estudos e pesquisa sobre Meio Ambiente e Espaço Urbano (GIPMAUR) Universidade do Extremo Sul Catarinense (UNESC). Criciúma, SC, Brasil - E-mail: tmg@unesc.net

\section{RESUMO}

Este estudo procura resgatar a cultura ancestral indígena nas imagens da cidade na perspectiva da reconstrução da memória coletiva e a construção de uma linguagem significativa que possa contribuir para o fortalecimento da identidade de lugar. As ambiências urbanas relacionam-se aos espaços construídos e habitados da cidade, cujos mais significativos acredita-se que sejam os públicos, como os parques e as praças. O locus da pesquisa foi o maior e o mais frequentado parque de uma cidade do Sul do Brasil. A pesquisa foi na modalidade qualitativa. Os aportes teóricos foram dados pela psicologia ambiental, design social e arqueologia.

Palavras-chave: Ambiências urbanas. Design social. Psicologia ambiental. Arqueologia. Identidade de lugar.

\section{ABSTRACT}

This study seeks to rescue the indigenous ancestral culture in the images of the city in the perspective of the reconstruction of collective memory and the construction of a significant language that can contribute to the strengthening of the identity of place. Urban environments are related to the built and inhabited spaces of the city, the most significant of which are believed to be public spaces, such as parks and squares. The research locus was the largest and most frequented park in a city in southern Brazil. The research was in the qualitative modality. The theoretical contributions were given by Environmental Psychology, Social Design and archeology.

Keywords: Urban environments. Social design. Environmental psychology. Archeology. Place identity. 


\section{INTRODUÇÃO}

A valorização e a apropriação do espaço público como estratégia para a humanização da cidade é uma das principais preocupações do Grupo Interdisciplinar e Interinstitucional de Estudos e Pesquisa sobre Meio Ambiente e Espaço Urbano (GIPMAUR), da Universidade do Extremo Sul Catarinense (UNESC), situada em Criciúma - SC, no âmbito do qual se desenvolveu esta pesquisa.

O Design Social tem como um de seus objetivos analisar as relações entre design e identidade local. Por sua vez, a psicologia ambiental tem como uma de suas teses que a identidade social se estrutura na relação da pessoa com o seu entorno sociofísico.

A partir dos pressupostos teóricos de uma psicologia crítica, a subjetividade é aqui entendida como a construção do mundo interno do sujeito a partir do interjogo dialético Homem/Mundo, o que define o seu próprio ser e a sua própria identidade.

As ciências sociais, entre elas a psicologia, levaram algum tempo para reconhecer a importância do entorno físico para a manutenção dos estados psicológicos positivos, que garantem a integridade da subjetividade e da identidade da pessoa. $\mathrm{O}$ espaço urbano deve propiciar experiências singulares e coletivas, tanto cognitivas quanto afetivas, pois ambas são básicas e precedem todo tipo de representação. É no espaço da cidade que a criança aprende a discernir o que é espaço público e o que é espaço privado.

Partindo da premissa de que todo ser humano tem direito aos bens materiais e imateriais da cidade, espaço escolhido pela maioria dos povos para nela viver, deve-se propiciar o acesso a esses bens, sendo os principais a arte, a cultura e os espaços públicos de fomento à vida pública informal.

A cidade em tela, ou seja, Criciúma - SC, locus deste estudo, é uma cidade ferida, no dizer de Freitag (2004). Sua atividade econômica, que teve início nas primeiras décadas do século XX, segue até os dias de hoje e já deixou um passivo ambiental de grande monta. Só muito recentemente e com o evento da legislação ambiental é que projetos de recuperação estão sendo desenvolvidos na região e nesta cidade. Contudo, tais projetos visam tão somente à recuperação do ambiente físico. Quanto ao patrimônio cultural, pouco se tem feito.

O objetivo desta pesquisa foi colocar em foco e valorizar os elementos culturais dos primeiros habitantes - os indígenas -, os quais legaram uma cultura que ainda permanece nos hábitos e nos costumes dos que habitam a região objeto deste estudo, como artefatos de 
pescaria, cestaria e vasilhas diversas, além de adornos pessoais que ainda hoje são vendidos nas praças.

Figura 1 - Jequi, artefato indígena para pescaria

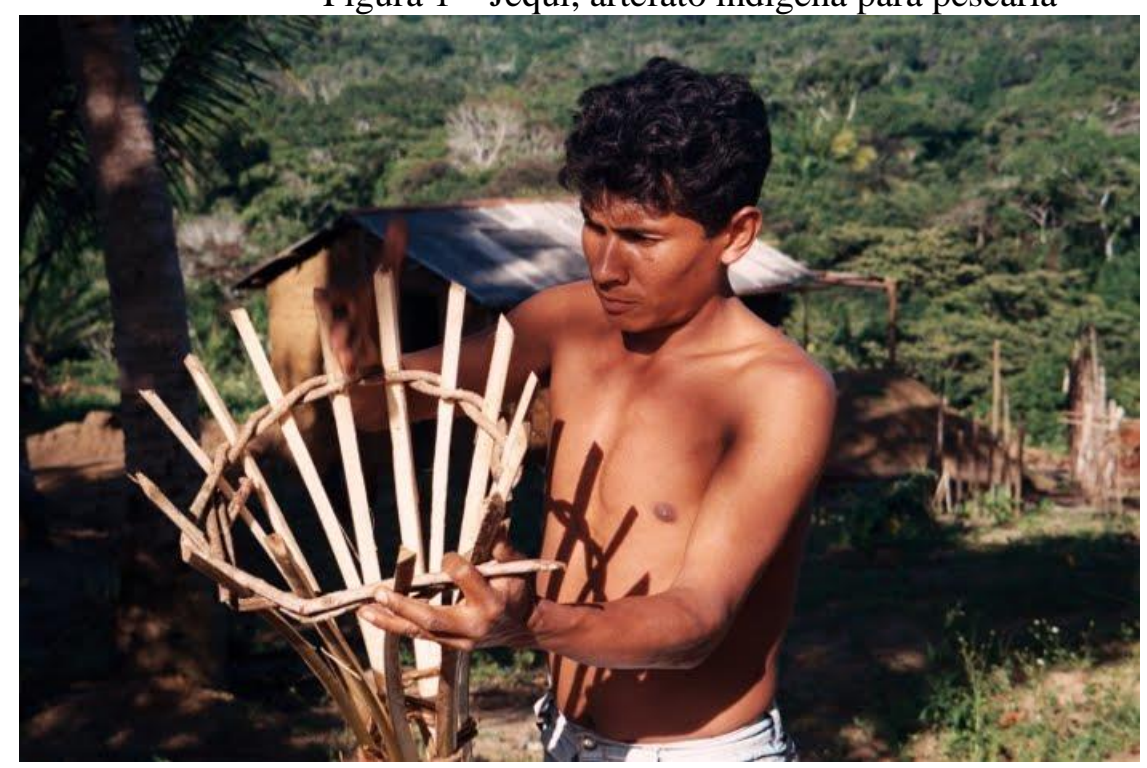

Fonte: <http://static.panoramio.com/photos/1920x1280/47279824.jpg>. Acesso em: 14 jul. 2014.

Essa perspectiva converge para a noção de que o espaço urbano é coletivo, ou seja, nele não se pode prescindir do outro em nenhum momento. A cidade com urbanidade tem uma dimensão ética, pois ela é a condição espacial da realização dos valores humanos solidários, forjados na coletividade e na vida pública, seja ela formal, seja informal.

As políticas públicas urbanas são condições efetivas do exercício da cidadania. A condição espacial para esse exercício são os espaços públicos, os espaços de fala - as praças, os parques, as calçadas, as ruas e os locais onde se edificam as instituições.

Por sua vez, o design social, numa visão crítica, não reduz seu trabalho ao mercado, propondo produtos que alimentam e incentivam o consumo pelo consumo.

Na discussão sobre design social, busca-se um referencial que permita uma interação e uma apropriação das culturas locais como referência no desenvolvimento de modelos e protótipos que agregam aos objetos o pensamento, a cultura e a cosmovisão, buscando, desse modo, compreender sua cultura, seus costumes e suas tradições.

Para falar de design social, de design cultural ou de design étnico, como alguns autores assim o preferem, queremos antes fazer uma reflexão sobre o estado da arte e o papel do designer no mundo contemporâneo, que é atravessado pelo processo de globalização e gera um fator competitivo, colocando-se como contradição para o designer. Nesse sentido, esse 
deve estar atento às novas tecnologias, a fim de gerar tal competitividade e, ao mesmo tempo, ter a preocupação ética de proteger o patrimônio cultural e as culturas locais e regionais para, com isso, trazer um referencial.

Nesse contexto, o designer desempenha um papel determinante, pois busca promover soluções inovadoras, estimulando a valorização dos produtos locais e as qualidades do território. Seria, na perspectiva de Krucken (2009), o conhecimento incorporado ao produto.

Esse entendimento é uma forma de contribuição para tornar visível à sociedade a cultura e a história por detrás do produto. A região em que se insere a cidade cenário da pesquisa é habitada há pelo menos 4.000 anos por populações de diferentes origens, culturas e histórias. Desde os povos ocupantes dos sambaquis do litoral atlântico, os caçadores-coletores da Mata Atlântica, os ceramistas e construtores de estruturas subterrâneas e de aterros do planalto e os ceramistas horticultores do litoral (SANTOS; PAVEI; CAMPOS, 2016; SANTOS; MILHEIRA, CAMPOS, 2017).

Atualmente, o território catarinense é habitado por grupos indígenas descendentes dessas primeiras populações, quais sejam: os Jê Meridionais (Kaingang e Xokleng) e os Guarani Mbyá e Guarani Nadeva ${ }^{1}$, que contribuem de forma fundamental para o incremento da diversidade e da riqueza cultural do estado. Dessas, optou-se, neste trabalho, por realizar o projeto de design a partir de elementos gráficos presentes no contexto cultural Kaingang, escolha que se deu principalmente pela maior facilidade de acesso imediato a informações em ambiente eletrônico (Internet) durante o processo de coleta de dados para a elaboração do projeto.

Este trabalho não tem a pretensão de contar a história desses povos, que tiveram sua população drasticamente reduzida durante o processo histórico de contato com os colonizadores europeus a partir do século XVI, por meio de epidemias, escravização e extermínio em massa. Seu objetivo é mostrar a possibilidade de, por meio de imagens e de símbolos, sensibilizar os usuários do espaço urbano, de maneira lúdica e poética, quanto aos traços históricos e culturais desses povos. Portanto, trata-se de um projeto inicial que se propõe a apontar para o potencial do tema. Uma continuidade dele pode, por exemplo, trabalhar em conjunto com os grupos indígenas atuais presentes na região, tanto nas aldeias quanto transitando pelos espaços urbanos, reconhecendo o valor técnico e estético de suas

\footnotetext{
${ }^{1}$ Para consultar a situação de tais povos atualmente conferir: 〈https://pib.socioambiental.org/pt〉. Acesso em: 20 set. 2017.
} 
manifestações culturais e construindo oportunidades que, ao mesmo tempo que buscam humanizar o espaço urbano, também possibilitam o reconhecimento do outro como produtor de cultura, estimulando a tolerância e a solidariedade.

Como o objetivo foi desenvolver, de forma interdisciplinar, um projeto de design para a valorização da cultura indígena, o qual foi apresentado à prefeitura local e aceito, a pesquisa sobre as culturas foi feita por meio de bancos de dados on-line, disponibilizados na Internet. A maior riqueza, entretanto, foi a discussão e as reflexões geradas no âmbito do grupo de pesquisa, por ocasião da elaboração do projeto.

A estratégia foi propor a revitalização de um parque, o maior e mais frequentado da cidade de Criciúma, buscando a memória cultural dos primeiros habitantes da região, no caso, as populações indígenas. Essa cultura estaria concretizada no mobiliário urbano do parque, cujas ambiências, quer nas áreas livres para encontro e prática de esportes, quer nas áreas cobertas, estariam mobiliadas também com elementos dessa cultura. O trabalho faz uma leitura que se liga com o campo do saber da psicologia ambiental, do design social e da arqueologia, tomando como campo de partida as relações entre a produção desses saberes, as linguagens daí decorrentes e a construção da paisagem da cidade e dos espaços públicos.

\section{ENCAMINHAMENTO CONCEITUAL}

A psicologia ambiental trabalha, fundamentalmente, com o conceito de espaço e com a apropriação desse (PROSHANSKY; FABIAN; KAMINOFF, 1976; POL, 1996). O objeto da psicologia ambiental é o estudo das relações do sujeito com seu ambiente sociofísico.

$\mathrm{O}$ lugar tem um significado para o indivíduo que o incorpora à própria identidade. $\mathrm{Na}$ construção da identidade, existem dimensões e características do entorno físico, que são incorporadas pelo sujeito por meio da interação com o ambiente. Nesse sentido, a identidade de lugar é um componente específico do próprio "eu" do sujeito, forjado em um complexo de ideias conscientes e inconscientes, sentimentos, valores, objetivos, preferências, habilidades e tendências (GONÇALVES, 2007).

A formação da identidade de lugar é decorrente da apropriação do espaço. Essa, por sua vez, é compreendida como o sentimento de possuir e gestionar um espaço por uso habitual ou por identificação, com o conceito de espaço, abarcando os espaços físicos, sociais, psíquicos e culturais. "Um sujeito, ao apropriar-se de um lugar, com o tempo, deixa sua marca 
e, ao transformá-lo, inicia um processo de reapropriação com o ambiente, colocando nele objetos com o qual se identifica" (GONÇALVES, 2007, p.28-29).

Cada sujeito se apropria de um lugar de forma diferenciada, dependendo, portanto, de modelos culturais, sociais, estilo de vida, entre outros.

Os processos de apropriação são complexos e se dividem em dois aspectos fundamentais: comportamentais de ação-transformação e de identidade de lugar simbólica - identidade do sujeito com o espaço, na qual se incluem os processos afetivos, cognitivos e interativos (GONÇALVES, 2007, p. 29).

Para Baudrillard (1969), o que escapa de essencial ao designer é o reconhecimento do fato de que os objetos imbuídos de significados adquirem vida própria. O caráter simbólico transcende o funcional. De certa forma, os objetos do design estão ligados diretamente ao homem e aos sistemas de significados que sedimentam sua cultura.

A arqueologia nos mostra isso de maneira contundente, por meio do estudo da materialidade do comportamento humano e, na maioria das vezes, do trato com artefatos materiais que se mantiveram "anônimos" por séculos ou até milênios. Isso demonstra o quão amplo é, tanto do ponto de vista da temporalidade quanto da diversidade cultural, o leque de possibilidades e da participação dos elementos materiais da cultura na vida em sociedade, desde os tempos mais remotos da trajetória humana até os dias atuais.

O autor ressalta a importância dos objetos antigos, porque contradizem o raciocínio funcional e cumprem o propósito de trazer à tona a sobrevivência do tradicional e do simbólico por meio do testemunho vivo, que não vai deixar morrer a lembrança de sua história e vai compor, com esse testemunho, o grande mosaico da existência humana, trazendo para o presente uma história negada pelos objetos funcionais modernos.

Os objetos antigos, afirma Baudrillard (1969), ostentam signos. Esses objetos, muitas vezes, são desprezados em virtude de no tempo moderno contemporâneo não terem mais função, sendo, por isso, relegados a meros objetos decorativos. Sua grande função, diz o autor, é vivida de outra maneira, como presença autêntica de um momento da história, por isso são carregados de significados e de historicidade, não são pedaços; são totalidade.

A presença do objeto antigo devolve ao homem a familiaridade, fazendo com que esse se sinta em casa, num ambiente acolhedor. A presença do objeto antigo funcionaria como um reorganizador do mundo, um testemunho do passado que existiu e continua no tempo presente. 
Sendo assim, se as espacialidades determinam comportamentos, os objetos antigos, ao contrário do objeto funcional, que se esgota na cotidianidade, trazem o passado como repertório e nos ambientes funcionam como um talismã, porque são densos. Trazem em si algo como se fosse o "inconsciente" do antigo, assim como a sabedoria dos anciãos.

Seguindo esse raciocínio, Baudrillard (1969) nos revela que os objetos em geral funcionam como espelhos, já que não emitem imagens reais, mas aquelas por nós desejadas.

A boa forma, tão propalada pelo design moderno, produz o objeto funcional, que é o enquadramento do criativo no clichê para produzir objetos homogêneos, num processo global que se constitui quase como em um cenário para esses objetos pasteurizados, mas que, pela força do mercado, convertem-se em quase “atores" e, ainda segundo o autor, em homem moderno, pois, em vez de manipular objetos, é por eles manipulado. Isso se explica pela uniformização de padrões, tanto de consumo como de comportamento, que o mundo globalizado impõe às pessoas.

Para o autor, os objetos não têm uma relação direta por si só com o usuário. É o usuário quem determina sua funcionalidade, criando, assim, um sistema entre eles em que ambos coexistam. Na atualidade, tem-se perdido essa capacidade e, segundo esse parâmetro, a sociedade tem procurado suprir tal carência com o consumismo, suprindo tanto o valor simbólico como o semiótico e o valor afetivo com uma aparente necessidade de adquirir novos objetos, os quais chegam às suas mãos sem alma e sem uma relação entre os diversos utensílios, cumprindo uma simples função prática.

$\mathrm{Na}$ atualidade, a personificação dos objetos em meros termos estéticos é o material inicial para sedimentar o intento de gerar seus próprios "ecossistemas", na perspectiva de obter uma sensação que não se consegue compreender, uma necessidade inconsciente que não se consegue expressar e, assim, alcançar uma apropriação com nossos contextos para que, dessa forma, deem serenidade e bem-estar, os quais são instintivamente almejados. Isso devido à atual carência de alma dos objetos.

Nesse sentido, o contraponto apresentado neste trabalho é feito por meio do objeto artesanal, o objeto da cultura indígena, que não é uma mera reprodução, mas um referente direto dessa alma e desse coração que a produção massiva perdeu.

É por isso que Baudrillard (1969) afirma que a personificação, a caracterização, não pode ser deixada ao acaso como o artesanato, cujas mãos do artesão entregam esse espírito de maneira automática. Sob parâmetros industriais, deve-se planejar e projetar objetos imbuídos 
dessa afetividade, para, assim, sistematizar essa produção e parar de inundar o mercado com banalidades que não atendem ao sentido emocional e até mesmo espiritual da vida humana, com os objetos decorando, ou melhor, conformando os seus contextos.

O contexto mais próximo dos objetos na cotidianidade das pessoas é a casa. Essa, segundo Valadares (2000), é carregada de simbolismo. Cugini (2010), referenciando-se em Baudrillard (1969), traz a importância de considerar a relação dos objetos com as ambiências que o homem cria. Os objetos passam a compor os ambientes e são mais um elemento que passa a figurar na trama das relações aí estabelecidas. São parte desse contexto chamado lugar, parte dessa interação que Baudrillard (1969) descreve.

Para esse autor, os objetos que compõem ambientes são partes desse sentimento de pertença, dessa harmonia quase imperceptível, mas que, no final, gera um desejo inconsciente de permanecer em determinados espaços. Isso estimula interações humanas diferentes, criando uma "morada", dá-se a partir dos mesmos padrões e cores que devem ter certas características, as quais facilitam, permitem e priorizam esses sentimentos e sensações, dependendo do contexto para o qual foram criados, e ratifica sua presença.

\section{A RELAÇÃO PESSOA-OBJETO}

Para Baudrillard (1969), a relação que as pessoas estabelecem com os objetos são mais importantes que os objetos em si. Os objetos são vividos cotidianamente com as pessoas e passam a integrar o seu modo de vida funcional e simbolicamente.

A concepção mental do objeto se funde com a cultura e com os rituais que envolvem os atos de sua vida. Quando um objeto é projetado nessa concepção, passa a ter outro sentido para quem o projeta. O copo para a cerimônia do chá no Japão, por exemplo, reveste-se de um significado especial, diferentemente de outro objeto cuja intenção de quem projeta é meramente funcional.

Entender a linguagem dos objetos é de suma importância para o design industrial, pois a função, na perspectiva do objeto, somente é conseguida quando esse objeto interage dentro da cultura de um grupo, o qual se relaciona com ele no âmbito de um sistema marcado pela dinâmica do consumo.

\section{CULTURA E SUBJETIVIDADE: OS MEIOS DE COMUNICAÇÃO DE MASSA}


Para melhor compreender essas questões, recorre-se a Nestor Garcia Canclini (2002, p. 41), que chama a atenção para as novidades dos estudos urbanos e de comunicação: "A cidade não é mais vista como um mero cenário, ou seja, como simples organização espacial para o assentamento da habitação da indústria e dos serviços".

Da mesma forma, os meios de comunicação não podem mais ser vistos como redes invisíveis que divulgam e transferem recursos tecnológicos, compondo as estratégias empresariais. As redes de comunicação nas megalópoles, por exemplo, reorganizam os usos da cidade por meio das informações e do entretenimento que leva aos domicílios.

Uma explosão de informações parte rumo às periferias da cidade que, segundo Canclini (2002), faz com que os seus habitantes percam o sentido dos limites de seu território. As notícias dos lugares mais distantes da cidade chegam às casas das pessoas por fragmentos, mas, ao mesmo tempo, costuradas pela linguagem da mídia.

Do passeio de flâneur, que reunia informações sobre a cidade para depois transferilas às crônicas literárias e jornalísticas, passamos, em 50 anos, ao helicóptero, que sobrevoa a cidade e oferece, a cada manhã, através da tela do televisor e das vozes do rádio, o panorama de uma megalópole vista em conjunto, como uma unidade recomposta por quem vigia e informa (CANCLINI, 2002, p. 41).

A cidade de hoje não é mais a cidade de Baudelaire (1996), cujo flâneur é um personagem e, ao mesmo tempo, um emissário. O processo de urbanização desigual que cria na América Latina desequilíbrios tanto espaciais quanto sociais e culturais cria também incertezas engendradas por uma urbanização que desurbaniza, principalmente porque segue uma lógica irracional e especulativa. O pacote telemático da mídia encarrega-se de narrar e descrever a cidade.

A cidade fragmentada dá a ilusão de que segue uma continuidade através de pontos sustentados por traços viários, e isso, no dizer de Sennett (1994), faz com que tenhamos a impressão de estarmos atravessando a cidade em um trem veloz e as paisagens correrem ao nosso redor e não conseguirmos nos deter em nenhuma delas.

No dizer de Castells (1983), trata-se de um não se deter; de circular e não parar, vagar, perambular. Barbero (1987) traz que a maior preocupação dos urbanistas não é com o caos urbano, com a falta de políticas públicas urbanas, com os efeitos da degradação ambiental, social e a perda da qualidade de vida urbana, mas sim planejar a cidade para que as pessoas circulem; “[...] ampliar e integrar avenidas, manter o fluxo" (BARBERO, 1987, p. 25). 
Assim, os centros históricos foram destruídos. As praças e os lugares que mantinham viva a memória e permitiam o encontro das pessoas, no dizer de Canclini (2002), diminuíram suas forças ante a remodelação dos imaginários, operada pelos meios de comunicação.

Os relatos mais influentes sobre o que significa a cidade emergem agora da imprensa, do rádio e da televisão. No tumulto heterogêneo e disperso de signos de identificação e referência, os meios de comunicação não propõem uma nova ordem, mas sim oferecem um espetáculo reconfortante (CANCLINI, 2002, p. 42).

Em vez de propiciar lugares de pertencimento, de identificação e raízes, o importante para a mídia é pôr o povo em movimento, ditando regras de comportamento e direcionando as atividades que cada grupo deve fazer. E, assim, os meios de comunicação ajudam a imaginar uma sociabilidade que relaciona comunidades virtuais de consumidores mediáticos.

\section{PROPOSTAS DE MOBILIÁRIO URBANO PARA O PARQUE INSPIRADO NOS DESENHOS INDÍGENAS}

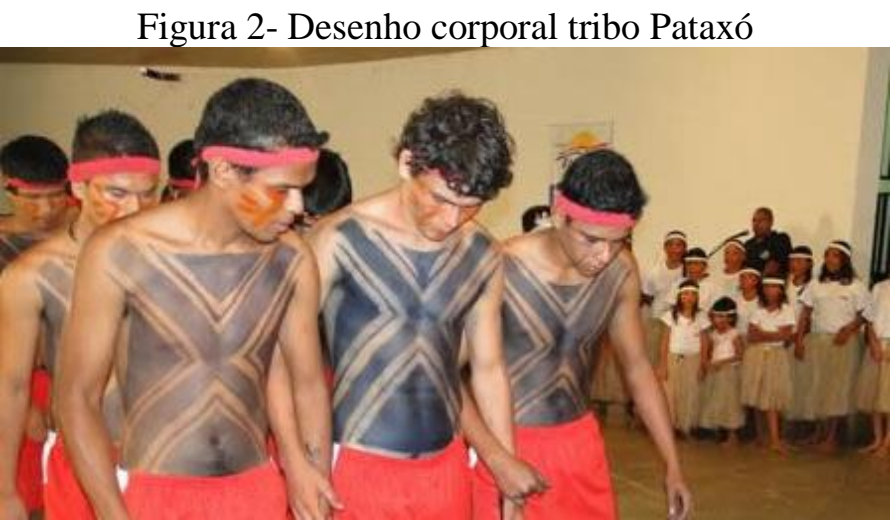

Fonte: <http://unisite.com.br/tupa/banco/2010/04/20/ce4b0b56f7fc81 da622d2f4b09d260ed.jpg >. Acesso em: 14 jul. 2014.

Figura 3 Mobiliário inspirado no desenho da tribo Pataxó 


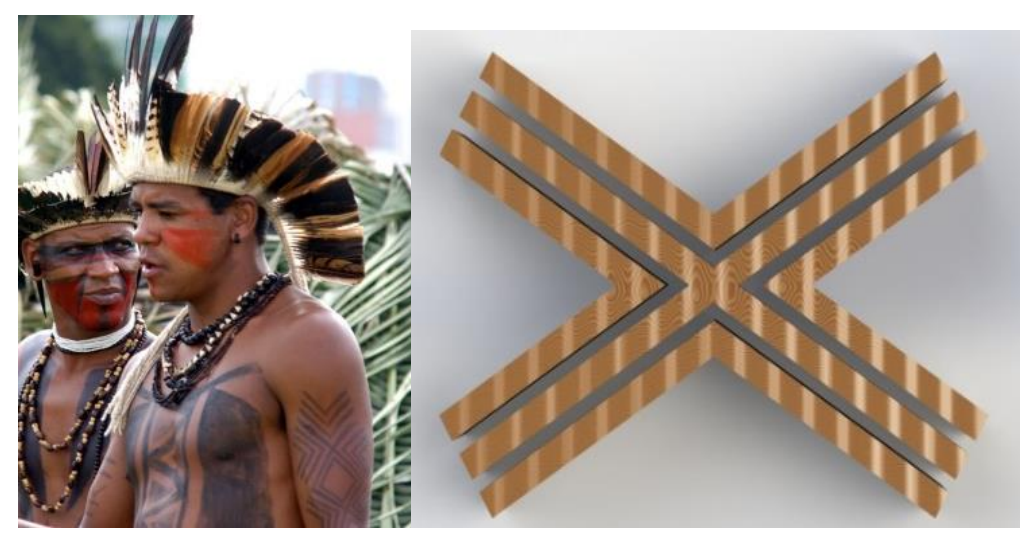

Fonte : <http://blog.maisestudo.com.br/wp-content/uploads/2011/05/Pataxo1.jpeg>. Acesso em: 14 jul. 2014. Fonte: Acervo de Santiago Alarcón Acosta.

Figura 4 Temática indígena em jogo de xadrez
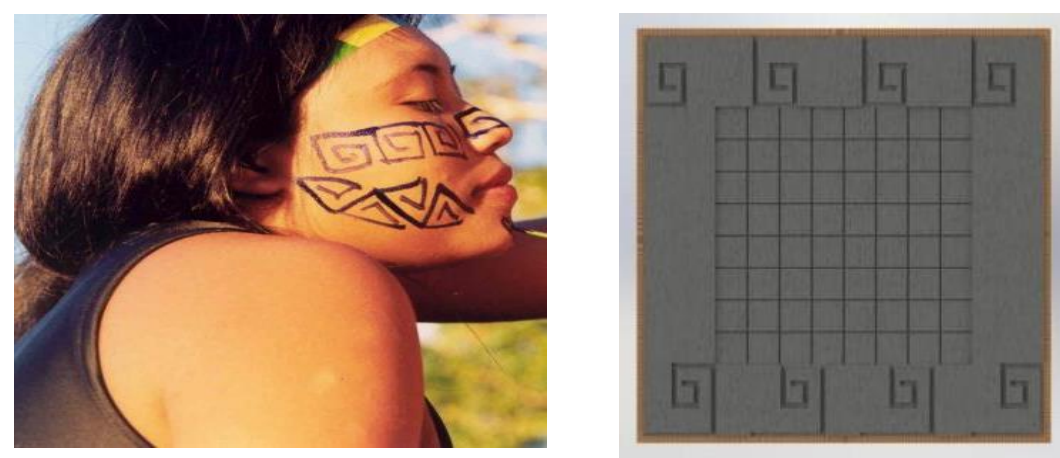

Fonte (d): <http://pib.socioambiental.org/fotos/7835_20091223_140556.jpg>. Acesso em: 14 jul. 2014.

Fonte: Acervo de Santiago Alarcón Acosta.

Figura 5 - Proposta e resultado de mobiliário conforme desenhos da tribo pataxó

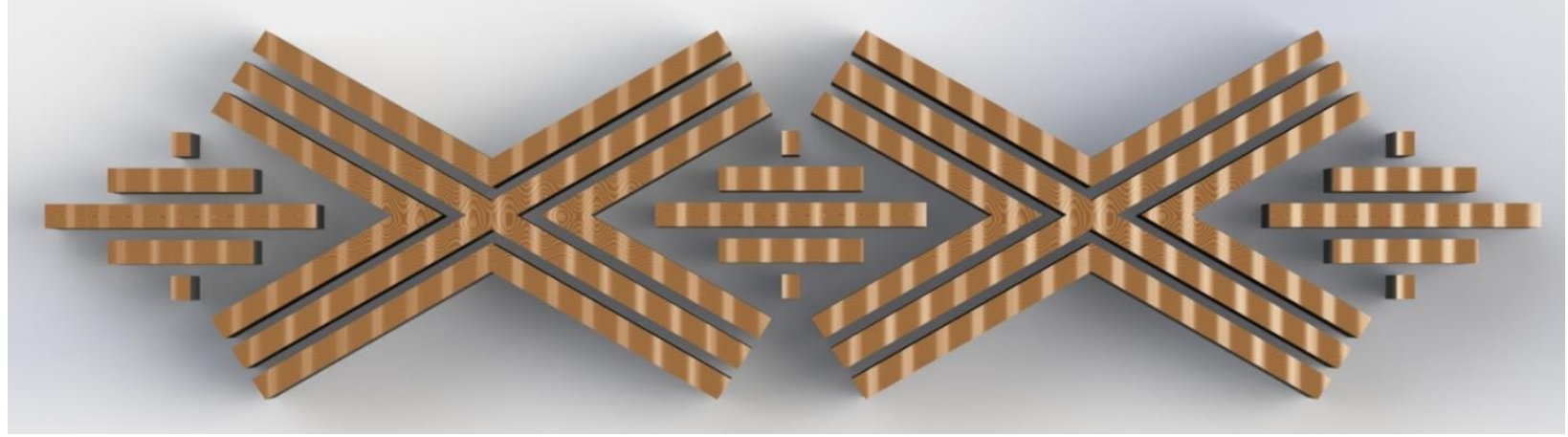

Fonte: Acervo de Santiago Alarcón Acosta.

Figura 6 Espaço proposto e espaço de convivência atual do parque

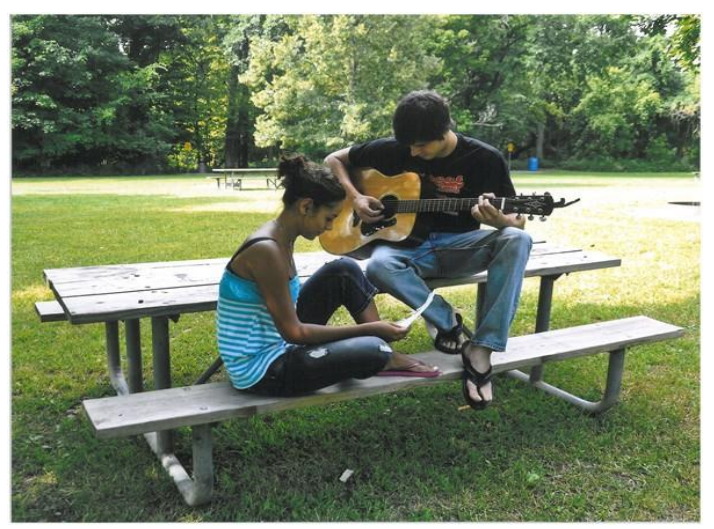




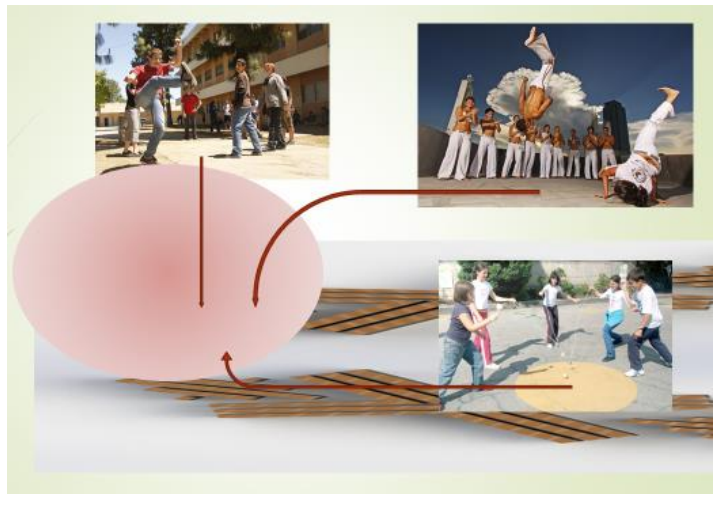

Fonte: Acervo de Santiago Alarcón Acosta.

Fonte (c): <http://upload.wikimedia.org/wikipedia/ commons/f/ff/Mensch.jpg>. Acesso em: 14 jul. 2014.

As diferentes disposições dos bancos permitem que as pessoas interajam com os objetos e com o espaço da melhor forma que elas precisem, gerando locais apropriados para muitas atividades, já que são de uso bidirecional. Isso proporciona versatilidade e diversidade.

\section{CONSIDERAÇÕES FINAIS}

A valorização das culturas indígenas materializadas em objetos concretos compondo espaços e cenários urbanos passará a fazer parte do contexto chamado lugar e é parte da interação que Baudrillard (1969) descreve. Para o autor, isso gera interações humanas diferentes, criando uma "morada", e se dá a partir dos mesmos padrões e cores que devem ter certas características que facilitam, permitem e priorizam sentimentos e sensações, dependendo do contexto para o qual foram criadas, e, assim, ratificam sua presença. A perda de essência dessa substância de "alma”, que já não se expressa mais nas paisagens e cenários urbanos, empobrece a vida pública informal do solo gerador para o exercício da cidadania.

A intenção deste projeto foi buscar a valorização de culturas tradicionais que compuseram um espaço ancestral e natural da região carbonífera de Santa Catarina, onde está localizada a cidade de Criciúma, mas que foram dizimadas. Busca-se um equilíbrio entre o passado e o presente, uma identidade não mais fragmentada, menos superficial e mais afetiva de uma população carente de habitat.

A cidade se faz representar e se dá a conhecer pelas suas imagens. As imagens urbanas são signos da cidade e atuam como mediadoras do conhecimento sobre essa. Signos entendidos como unidade linguística construída pela associação de um significante e de um 
significado. O significante é o que significa, nesse caso o sujeito. Significado é o sentido dado pelo sujeito e concretamente expressado.

Memória pessoal e social, sentimento de pertença, fruição e experiências estéticas, portanto integradoras da consciência, são algumas das questões que se mostram decorrentes da importância significativa da cultura nos estudos das ambiências urbanas. Espera-se que traços da cultura indígena, que floresceram um dia nessa região, concretizados no mobiliário urbano do parque, possam contribuir para o processo construção da identidade urbana na cidade de Criciúma.

\section{REFERENCIAS}

BARBERO, M. J. De los médios a las mediaciones: comunicación, cultura y hegemonía. México: G. Gili, 1987. BAUDELAIRE, C. Sobre a Modernidade. Rio de Janeiro: Paz e Terra, 1996. BAUDRILLARD, J. EI sistema de los objetos. México: Siglo XXI, 1969.

CANCLINI, N. G. Cidades e cidadãos imaginados pelos meios de comunicação. Revista Opinião Pública, Campinas, SP, n. 1, v. VII, p. 40-53, 2002.

CASTELLS, M. La ciudad y las masas. Madrid: Alianza Editorial, 1983.

CUGINI, P. Os Sistemas dos objetos de Jean Baudrillard. 2010. Disponível em: <http://blogdafaculdade.blogspot.com.br/2010/04/o-sistema-dos-objetos-dejean.html>.

Acesso em: 18 out. 2013.

FREITAG, B. Etinerâncias urbanas. Brasília: Casa das Musas, 2004.

GONÇALVES, Teresinha Maria. Cidade e poética: um estudo de psicologia ambiental sobre o ambiente urbano. Ijuí: Unijuí, 2007.

KRUCKEN, L. Design e território: valorização de identidades e produtos locais. São Paulo: Nobel, 2009.

POL, E. La apropiación del espacio. In: INIGUEZ, L.; POL, E. (Orgs.). Cognición, representación y apropiación del espacio. Barcelona: Universitat Barcelona Publicacions, p, 1996. P.233-249

PROSHANSKY, H. M.; FABIAN, A. K.; KAMINOFF, R. Appropiation et nonappropiation (mis-appropriation) de l' space. [S.l.: s.n.], 1976.

SANTOS, J. dos; MILHEIRA, R. G.; CAMPOS, J. B. Entre Rios, Dunas, Lagoas e o Mar: Arqueologia Guarani no Litoral Sul Catarinense. Revista da Sociedade de Arqueologia Brasileira, São Paulo, p. 28-55, 2017.

SANTOS, M. C. P.; PAVEI, D. D.; CAMPOS, J. B. Arqueologia entre Rios: do Urussanga ao Mampituba - Paleoambiente, cultura material e ocupação humana na paisagem litorânea do extremo Sul catarinense entre 3.500-200 anos AP. Cadernos do CEOM, Chapecó (SC), v. 29, n. 45, p. 64-86, 2016.

SENNETT, R. Carne e Pedra. Rio de Janeiro: Record, 1994.

VALADARES, J. C. Qualidade do Espaço e da Habitação Humana. Revista Ciência \& Saúde Coletiva, Rio de Janeiro (RJ), v. 5, n. 1, 2000. 